"أهمية معرفة الأحكام الجممع عليها "

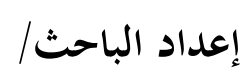

أشرف سيد محمد حسين

\title{
ا ملمقدة
}

الحمد لله رب العالمين والعاقبة للمتقين, والصلاة والسلام على سيد المرسلين سيدنا محمد

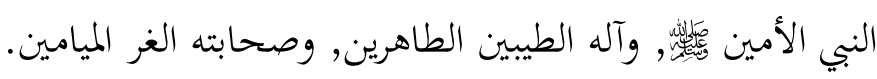
أما بعد:

فإن الإجماع من المصادر المعتبرة في الشريعة الإسلامية عند أهل السنة والجماعة؛ لما قام

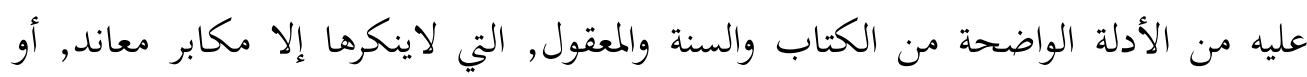
جاهل لا دراية له بعلوم الشريعة.

وباب الإجماع باب عظيم ينبغي على الباحث أن يكون على دراية بالأحكام المجمع

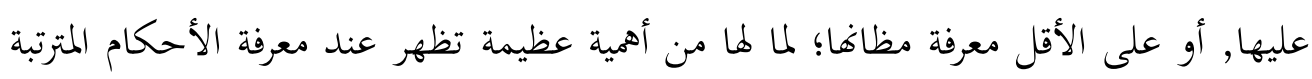

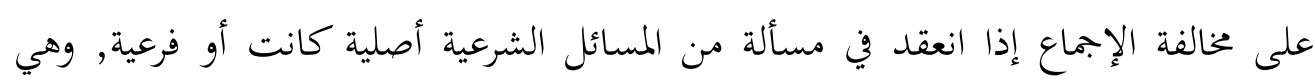

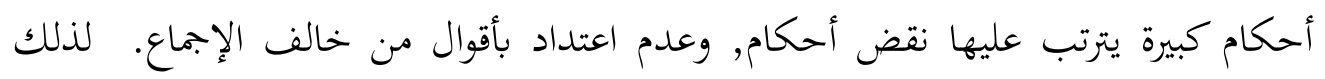
أحببت أن أبين في هذا البحث أهمية معرفة الأحكام الجممع عليها, تحت عندان أحسان (أهمية معرفة

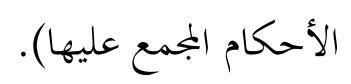

خطة البحث: يتكون البحث من مقدمة ومطلبين وخاتمة: المطلب الأول: الأحكام المتعلقة بانعقاد الإجماع. وفيه ثلاث مسائل: المسألة الأولى: تحريم مخالفة الإجماع. المسألة الثانية: نقض حكم القاضي إذا خالف الإجماع. 
المسألة الثالثة: اشتراط معرفة مواضع الإجماع لبلوغ مرتبة الاجتهاد.

المطلب الثاني: عناية الفقهاء بإفراد مواضع الإجماع بالتأليف قديما وحديثا:

وفيه نماذج للمؤلفات التي لها عناية بذكر مواطن الإجماع. 


\section{أهمية معرفة الأحكام البجمع عليها}

تظهر أهمية معرفة الأحكام المجمع عليها من خلال ما يترتب على الإماع من أحكام

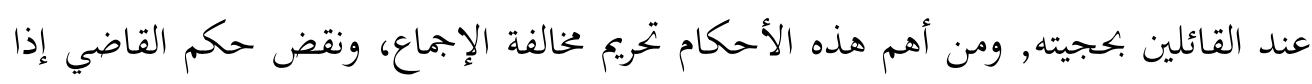

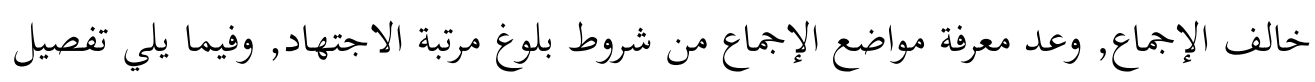
الكلام عن هذه الأمور في المطلبين التاليين:

المطلب الأول: الأحكام المتزتبة على انعقاد الإجماع:

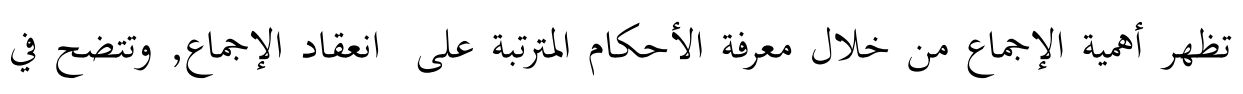
المسائل الآتية:

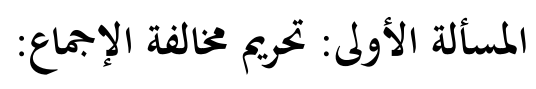

القول بتحريم خخالفة الإمماع مبني على القول بحجيته, فمن ينكر حجية الإمماع لا يتصور منه أن يحرم مخالفته.

أما القائلون بحجية الإماع: فهم متفقون على تخريم بخالفة الإماع)

قال الآمدي(2) -رحمه الله-: (فالجممع عليه إما ان يكون أمر من أمور الدين أو الدنيا،

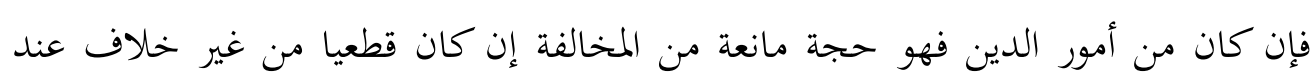

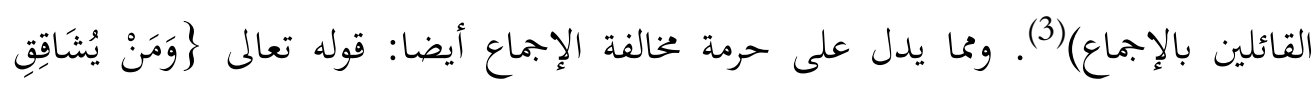

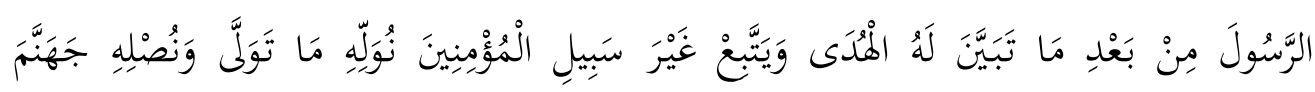

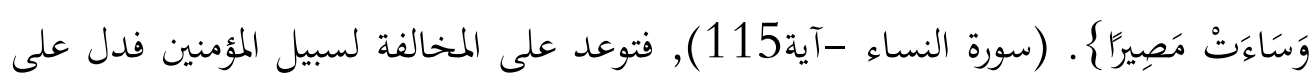
أن إجماعهم حجة واجب اتباعه ومخالفته حرام. المسألة الثانية: نقض حكم القاضي إذا كان مخالفا للإجماع: 
لا يتصور القول بنقض حكم القاضي عند من ينكر حجية الإماع بناءاً على القول

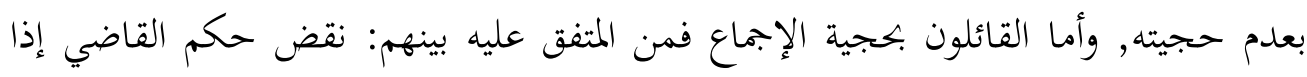
خالف الإجماع (4).

وقد حكى الإجماع على هذا الحكم شمس الدين الأصفهاني(5) في شرحه لمختصر ابن

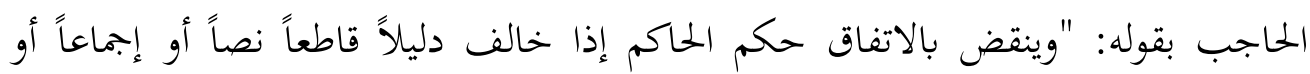

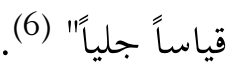

\section{المسألة الثالثة: اشتراط معرفة مواضع الإجماع لبلوغ مرتبة الاجتهاد:}

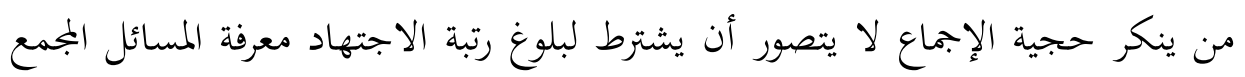

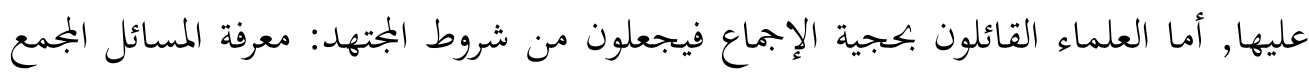

$$
\text { عليها حتى لا يخرق الإجماع (7). }
$$

قال الشوكاني -رحمه الله-: "الشرط الثاني: أن يكون عارفا بمسائل الإجماع؛ حتى لا يفتي

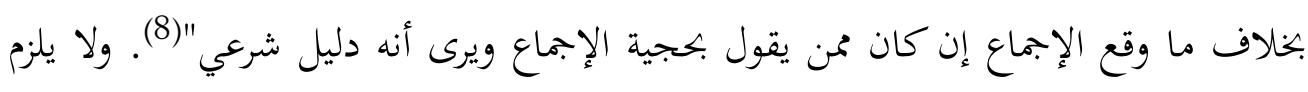

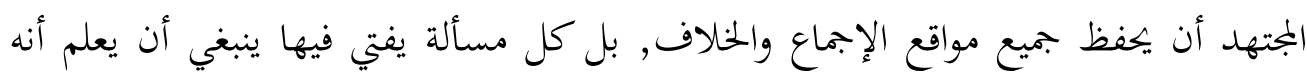

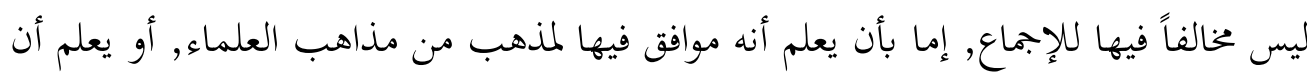
هذه المسألة حادثة لا يتصور فيها وجود إجماع سابق (9). المطلب الثاني: عناية الفقهاء بإفراد مواضع الإمماع بالتأليف قديمًا وحدينًا:

ونظرًا للأهمية الكبيرة لمعرفة الأحكام الفقهية المجمع عليها اعتى الفقهاء ببياها عناية

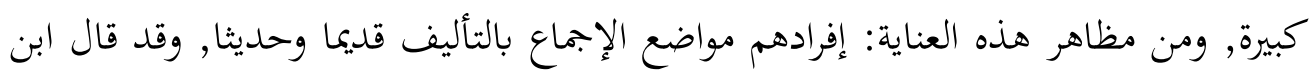

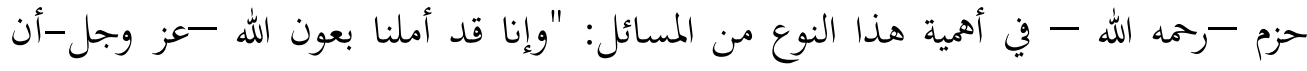

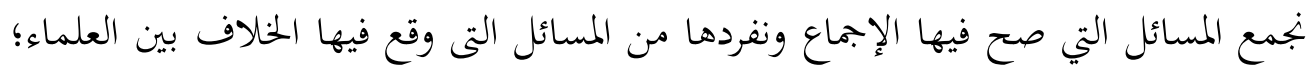

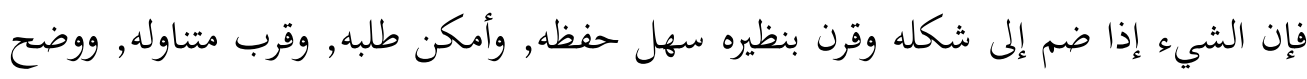


خطأ من خالف الحق به، ولم يتعن المتخصصون في البحث عن مكانه عند تنازعهم فيه"(10). وتتمة للفائدة أذكر فيما يلى بعض المصنفات الخاصة بمسائل الإجماع؛ لبيان عناية الأئمة بمواضع الإجماع في المسائل الفقهية خاصة قديما وحديثا, ولكثرتما يمكن يمكن تقسيمها بالنظر لئك إلى منهج تأليفها إلى ثلاثة أنواع:

$$
\text { النوع الأول: الكتب التي أفردت لذكر الأحكام المجمع عليها. }
$$

النوع الثالث: الكتب التي تذكر الإجماع والاختلاف في الأحكام الفقهية. وفيما يلي الكلام عن هذه الأنواع الثلاثة: 20 الث:

\section{النوع الأول: الكتب التي أفردت لذكر الأحكام البجمع عليها:}

وأعني بذا النوع الكتب التي خصصها مؤلفوها لذكر الأحكام الفقهية المجمع عليها في جميع الأبواب الفقهية دون المختلف فيها, فلا يذكرون فيها إلا ما أجمع عليها, وفيما يلي الكتب القديمة والحديثة التي وقفت عليها في هذا:

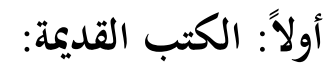

$$
\text { وقفت على كتابين من الكتب القديمة، وهما: }
$$

1- الإجماع، لأبي بكر محمد بن إبراهيم النيسابوري (ت 319), وقد قال ابن تيمة-

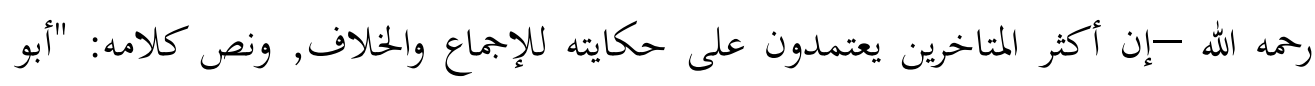
بكر بن المنذر عليه اعتماد أكثر المتاخرين في نقل الإجماع والخلاف" (11), وكتاب الإجماع لابن المنذر مرتب على أبواب الفقه حيث يذكر المؤلف في كل باب الإجماعات التي فيه. ويلاحظ

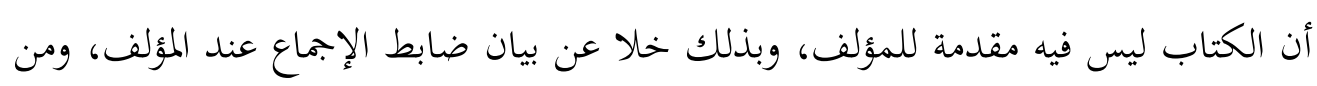
يعتد بهم في الإجماع ومن لا يعتد. 
2- مراتب الإجماع في العبادات والمعاملات والاعتقادات: لأبي محمد علي بن أحمد بن سعيد بن حزم (ت456هـ), وهذا كتاب مرتب على أبواب الفقه حيث يذكر المؤلف في كل باب الإجماعات التي فيه, مع إضافته بابا في الإجماع في الاعتقادات سماه: (باب من الإجماع في الاعتقادات يكفر من خالفه بإجماع), ويقع هذا الباب في صفحات قليلة, فهو يشكل جزءاً يسيراً من الكتاب, والكتاب مشتمل على مقدمة للمؤلف بين فيها عدة أمور: منها بيان أهمية الإجماع, وحكم مخالفه, وأهمية إفراد الأحكام المجمع عليها بالتأليف، وضابط الإجماع عنده, ومن يعتد بهم من العلماء في الإجماع ومن لا يعتد.

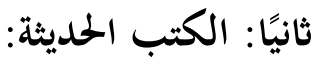

ومن الكتب الحديثة التى تدخل في هذا النوع: "موسوعة الإجماع في الفقه الإسلامى"، تأليف سعدي أبو حبيب، وقد قام المؤلف بحسب تعبيره: "بالتقاط مسائل الإجماع المتناثرة في

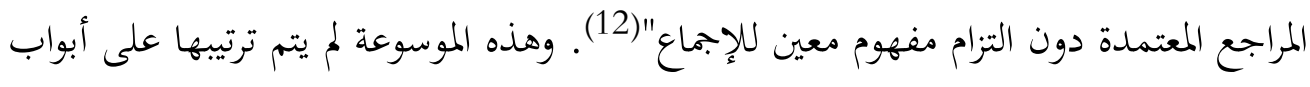
الفقه كحال الكتابين السابقين القديمين، بل قام المؤلف (بجمع المسائل ذات الموضوع الواحد تحت عنوان أصلي, مثل صلاة، صوم, يمين,... وترتيب هذه المواضيع وفق الترتيب الهجائي:

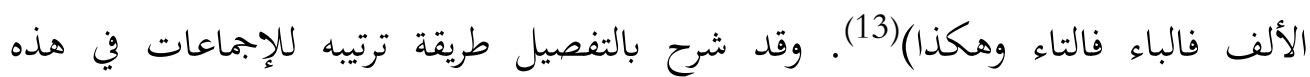
الموسوعة في بدايتها تحت عنوان: خطة العمل كما شرح مراده بالرموز التي استخدمها في الموسوعة تحت عنوان: الرموز (14).

\section{النوع الثالي: الكتب والدراسات عن إجماعات عالم معين:}

ومن الكتب القديمة التي وقفت عليها في هذا النوع: نقد مراتب الإجماع: لأبى العباس أحمد بن عبد الحليم بن تيمية (ت827هـ), وقد بين ابن تيمية-رحمه الله-في كتابه هذا الخلاف في كثير من المسائل التي حكى ابن حزم-رحمه الله- الإجماع عليها في كتابه مراتب لئب الإجماع في العبادات والمعاملات والاعتقادات, وصرح ابن تيمية بأنه لم يبين جميع الإجماعات التى حكاها ابن حزم في مسائل خلافيه بقوله: (وقد ذكر رحمه الله إجماعات من هذا الجنس 
من هذا الكتاب، لم يكن قصدنا تتبع ما ذكره من الإجماعات التى عرف انتقاضها، فإن هذا يزيد على ما ذكرناه) (15) من ملن.

\section{أما الكتب والدراسات الحديثة فمنها:}

الإجماع عند الإمام النووي من خلال شرحه لصحيح مسلم دراسة أصولية تطبيقية, رسالة ماجستير, إعداد: علي بن أحمد بن محمد العميري الراشدي, في جامعة أم القرى, كلية الشريعة, فرع الفقه وأصوله1419هـ, وقد اشتملت الرسالة في الجانب التطبيقي على جميع الإجماعات التي حكاها النووي - رحمه الله -في شرحه لصحيح مسلم(16), وقد قام منهج الرسالة على دراسة هذه المسائل والتحقيق من صحة الإجماعات التي حكاها النووي, فقد قال الباحث في منهجه (أراجع كتب المذاهب المشهورة لتأكيد الإجماع أو عدمه.. وعند وجود الخلاف في المسألة أثبت ذلك...)(17).

إجماعات ابن عبد البر دراسة فقهية مقارنة, رسالة ماجستير, إعداد: سيده عبده بكر عثمان, في جامعة القاهرة, كلية دار العلوم, قسم الشريعة الإسلامية 1421هـ / 2000م. والهدف من هذه الرسالة دراسة المسائل التي ذكر ابن عبد البر - رحمه الله- أفها مجمع عليها

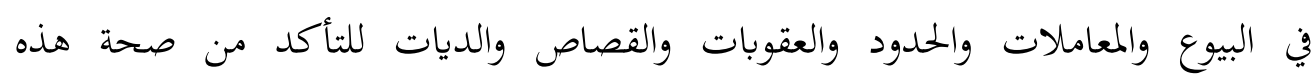
الإجماعات أو عدمها, فقد قال الباحث في مقدمة رسالته: (وفي هذا البحث عرض للمسائل التي ذكر أهما محل إجماع، وذلك في مجال هو من أصعب المجالات لتحقق الإجماع فيها, وهي البيوع, والمعاملات والحدود والعقوبات والقصاص والديات فأردنا عرضها ودراستها حتى يتبين وجه الحق فيها) (18).

الإجماع لابن عبد البر، جمع وترتيب: فؤاد بن عبد العزيز الشلهوب, وعبد الوهاب بن ظافر الشهري, وهو كتاب منشور, ومنهج الكتاب يقوم على جمع الإجماعات التي وردت في كتاب ابن عبد البر: التمهيد لما في الموطأ من الأسانيد من غير دراسة لهذه الإجماعات وبيات ونيان

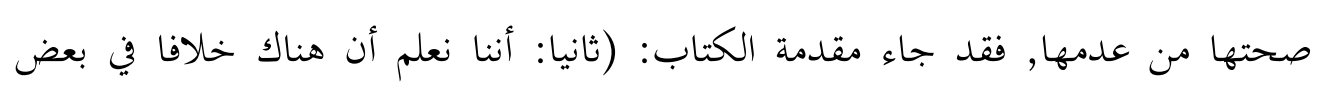


المسائل التي ذكر أها إجماع، ولكن آثرنا الإبقاء على عبارات الشيخ دون تعليق. ثالثا: كنا

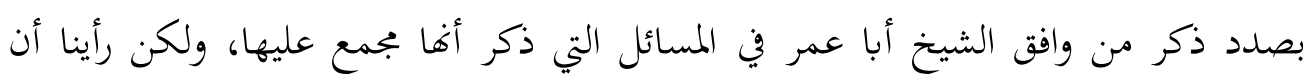
البحث سوف يطول, فآثرنا الاقتصار على ما جاء في التمهيد دون غيره) (19).

\section{النوع الثالث: الكتب التي تذكر الإجماع والاختلاف في الأحكام الفقهية:}

وهذا النوع يتكون من كتب الفقه المقارن التي تبين أقوال الفقهاء في المسائل الفقهية ذاكرة إجماعطم واختلافهم فيها على حسب ورودها في أبواب الفقه, فهي مرتبة على أبواب الفقه, ويدخل في هذا النوع -أيضا - كتب التفسير عند تفسيرها لآيات الأحكام, وكذلك تهن كتب شروح الحديث عند شرح أحاديث الأحكام أو شرح الكتب المؤلفة في أحاديث الأحكام.

والكتب المؤلفة في هذا النوع كثيرة كما لايخفى؛ لذا سأكتفي بذكر بعض أشهرها فيما

\section{من كتب الفقه المقارن:}

الأوسط في السنن والإجماع والاختلاف: أبي بكر محمد بن إبراهيم بن المنذر النيسابوري. المبسوط: شمس الأئمة أبي بكر بن محمد بن أحمد بن أبي سهل السرخسي(ت 483هـ). بداية المجتهد ونهاية المقتصد: أبي الوليد محمد بن أحمد بن محمد بن رشد الحفيد القرطبي,

$$
\text { (ت 595ه) }
$$

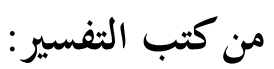

$$
\begin{aligned}
& \text { أحكام القرآن: لأبي بكر أحمد بن علي الرازي الجصاص, (ت 370هـ). } \\
& \text { أحكام القرآن: لأبي بكر محمد بن عبد الله بن العربي، (ت 543هـ). } \\
& \text { الجامع لأحكام القرآن, لأبي عبدالله محمد بن أحمد الأنصاري القرطبي (ت 671هـ). }
\end{aligned}
$$




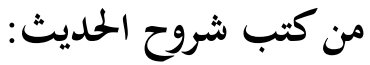

التمهيد لما في الموطا من المعاني والأسانيد, لأبي عمر بن يوسف بن عبد الله بن عبد البر

$$
\text { القرطبي (ت 463هـ). }
$$

$$
\text { شرح صحيح مسلم, لأبي زكريا يهيي بن شرف النووي, (ت 676هـ). }
$$

$$
\text { فتح الباري شرح صحيح البخاري، لأحمد بن علي بن حجر (ت 852هـ). }
$$

من هذه النماذج الكثيرة من الدراسات القديمة والحديثة - فيما يتعلق بمسائل الإجماعيتبين أن قضية الإجماع من ناحية الثبوت وعدمه تحتاج إلى اهتمام كبير من الباحثين, وتتبين أهمية معرفتها للباحث لخطورة المخالفة في شيء منها, و الله أعلم. والآن بفضل لله قد انتهيت من بحثي, فإن كان من توفيق فمن الله, وإن كان من خطأ فمن نفسي, أسال الله أن يغفرلي خطئي, والحمد لله رب العالمين.

\section{الحخاتمة}

$$
\text { أولاً: الإجماع مصدر من مصار الشريعة الإسلامية المعتبرة عند أهل السنة. }
$$

ثانياً: أهمية معرفة الأحكام المجمع عليها؛ لما يترتب عليها من أحكام من أهمها: أن مخالفة الإجماع محرمة, وأن القاضي إذا حكم بحكم يخالف الإجماع ينقض هذا الحكم ولا يعتد به. ثالثاً: أن معرفة الأحكام المجمع عليها شرط في بلوغ المجتهد مرتبة الإجتهاد. رابعاً: تظهر عناية العلماء قديماً وحديثاً بمسائل الإجماع في كثرة المصنفات التي صُنَّفت فيها وتنوعها, ما بين مؤلفات خاصة بمسائل الإجماع فقط, وما بين مصادر موسوعية تشمل مسائل الإجماع وغيرها, ككتب الشروح للسنة, والتفاسير, والفقه المقارن, فضلاً عن الدراسات 
الأكاديمية المتنوعة ما بين جمع لمسائل الإجماع في باب من أبواب الشريعة, أو جمع مع دراسة, أو تعقب وغير ذلك مما سبق بيانه في البحث.

خامساً: حاجة مسائل الإمماع إلى تنقية وتنقيح وتعقب لمن ينقلها لخطورة الأحكام

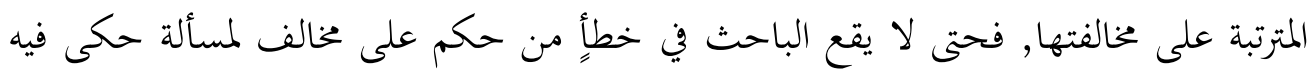

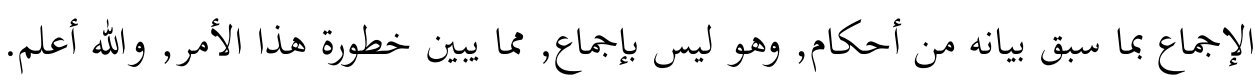

\section{المراجع}

1

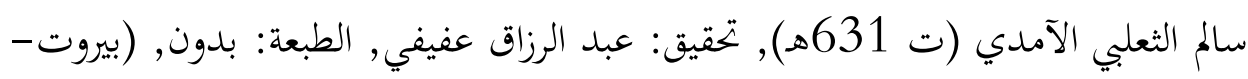
دمشق - لبنان, المكتب الإسلامي، التاريخ: بدون).

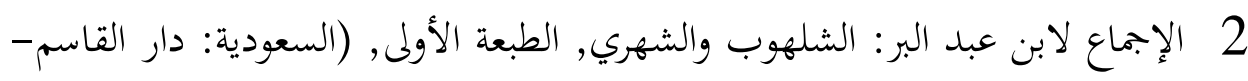

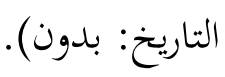

3 إرشاد الفحول إلي تحقيق الحق من علم الأصول: محمد بن علي بن محمد بن عبد الله

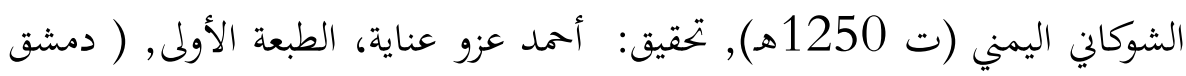

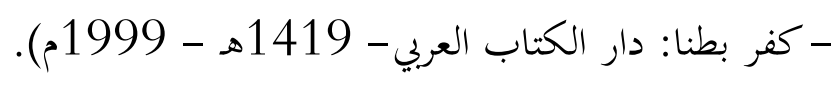

4 الأعلام: خير الدين بن محمود بن محمد بن علي بن فارس، الزركلي الدمشقي

$$
\text { (ت1396هـ) الطبعة: الخامسة عشر, (بيروت: دار العلم للملايين - } 2002 \text { م). }
$$

5

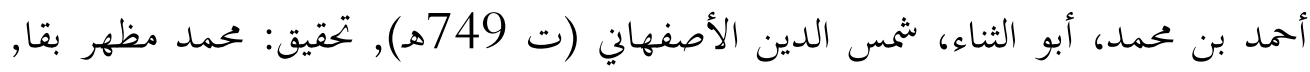

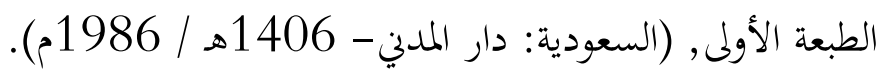

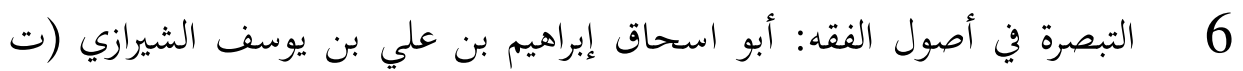
476هـ), تحقيق: محمد حسن هيتو, الطبعة الأولى، (دمشق: دار الفكر -1403هـ). 
7

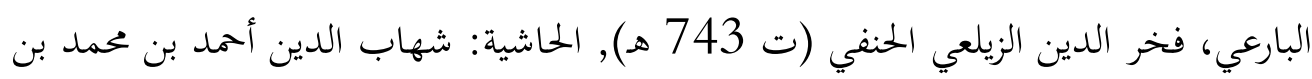

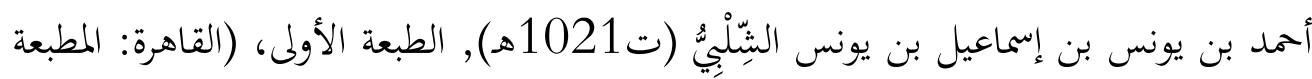

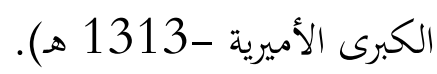

8

$$
\text { الطبعة الأولى، (الاسكندرية: دار الدعوة - (1403). }
$$

9

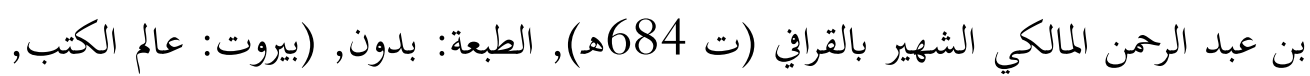

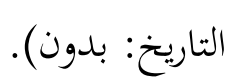

10 قواطع الأدلة في الأصول: السمعاني, تحقيق: محمد حسن محمد حسن اسماعيل

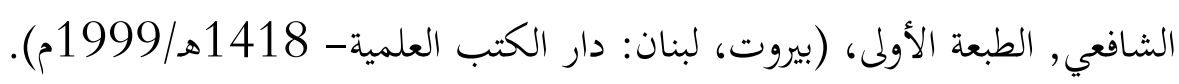

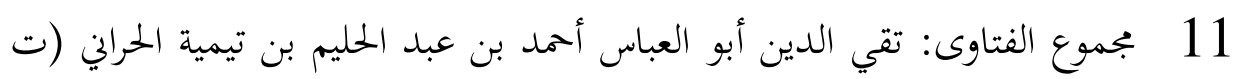

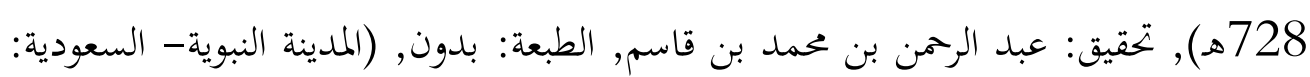

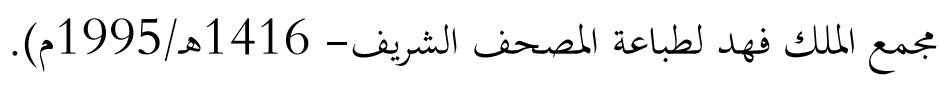

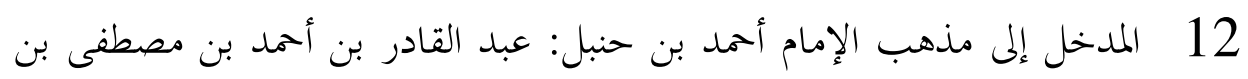

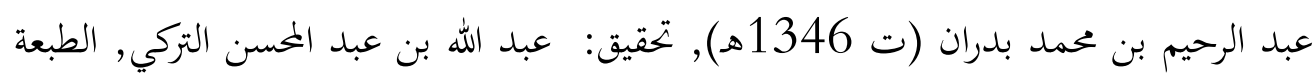
الثانية، (بيروت: مؤسسة الرسالة - 1401هـ).

13 مراتب الإمماع: أبو محمد علي بن أحمد بن سعيد بن حزم الأندلسي القرطبي الظاهري (ت 456هـ), الطبعة: بدون, (بيروت: دار الكتب العلمية, التاريخ: بدون).

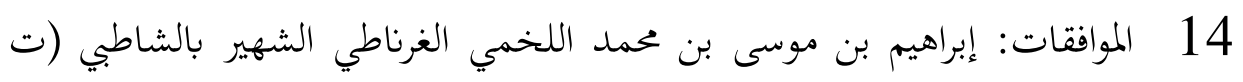

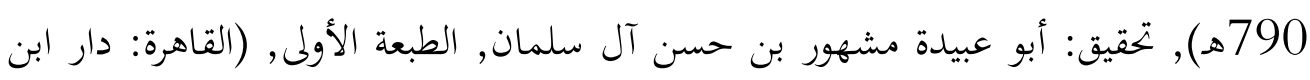

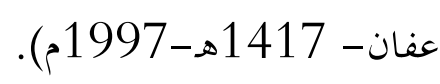


15 موسوعة الإجماع في الفقه الإسلامي: سعدي أبو حبيب, الطبعة الخامسة,

(بيروت: دار الفكر - 2005).

16 نقد مراتب الإجماع:ابن تيميه، تحقيق: حسن أحمد إسبر, الطبعة الأولى,

$$
\text { (بيروت: دار ابن حزم - 1419هـ - 1998م). }
$$

17

11 1 1 التبصرة في أصول الفقه: أبو اسحاق إبراهيم بن علي بن يوسف الشيرازي (ت 476هـ), تحقيق: محمد حسن هيتو,

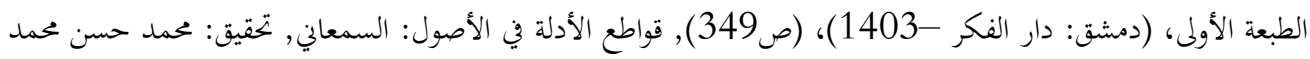

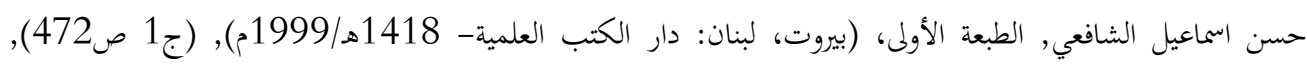

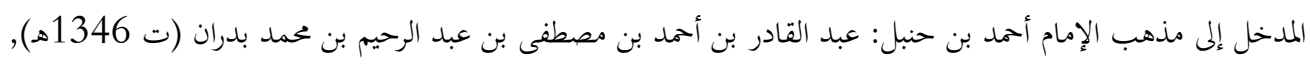

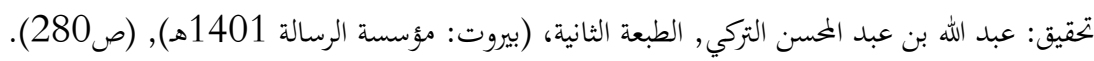

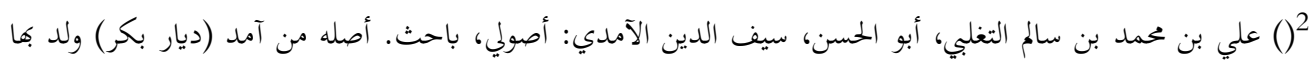

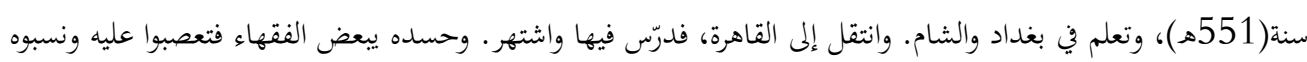

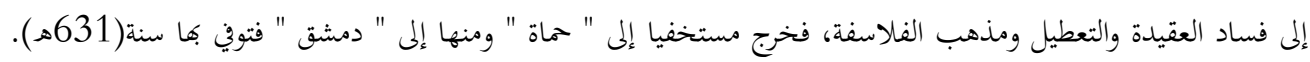

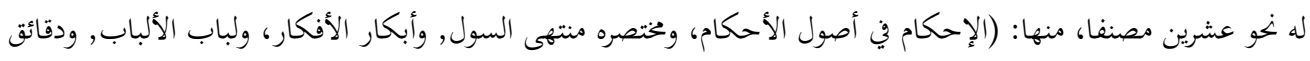

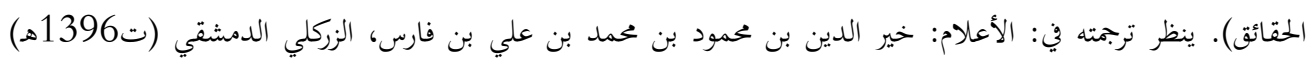

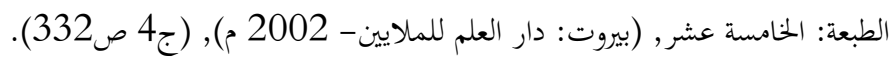
(3)الإحكام في أصول الأحكام: الآمدي, تحقيق: عبد الرزاق عفيفي, الطبعة: بدون, (بيروت: المكتب الإسبة الإسلامي، التاريخ:

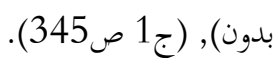
(4) ينظر: تبيين الحقائق شرح كنز الدقائق وحاشية الشَّبْبِّ: عثمان بن علي بن محجن البارعي، فخر الدين الزيلعي الحنفي

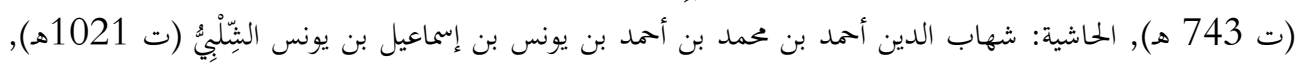

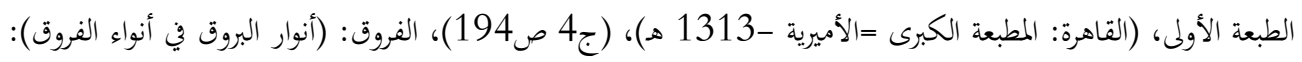

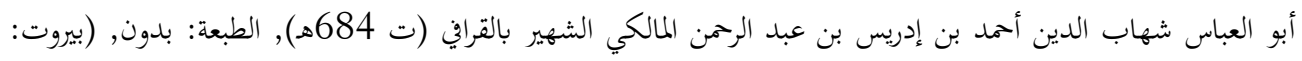

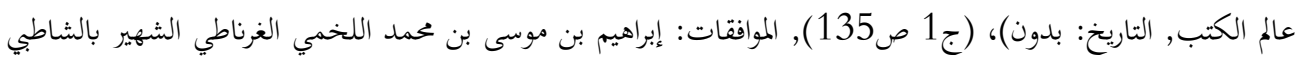

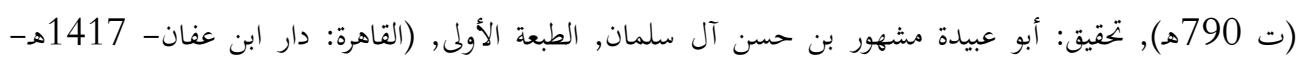

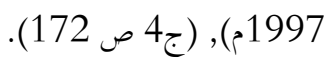

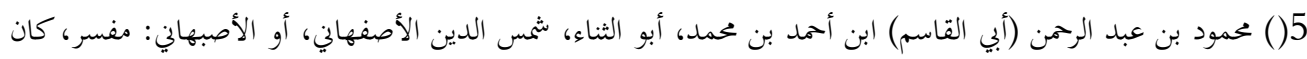

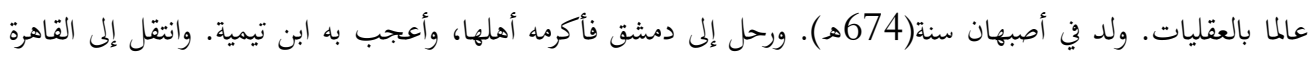

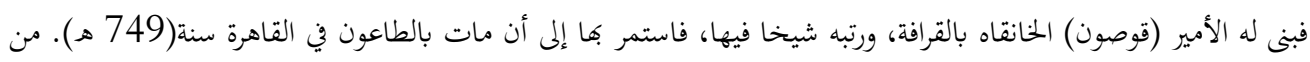


كتبه (التفسير، والبيان، وبيان معاني البديع، وشرح مطالع الأنوار، وشرح كافية ابن الحاجب, وشرح منهاج البيضاوي), ينظر

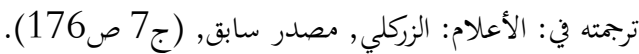
(66) بيان المختصر شرح مختصر ابن الحاجب: الأصفهاني, تحقيق: محمد مظهر بقا, الطبعة الأولى, (السعودية: دار المدني-

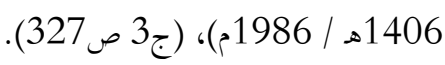

(7)المستصفى: أبو حامد محمد بن محمد الغزالي الطوسي (ت 505هـ), تحقيق: محمد عبد السلام عبد الشافي, [الطبعة:

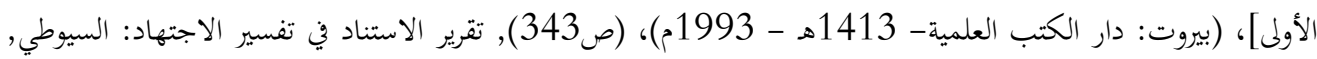

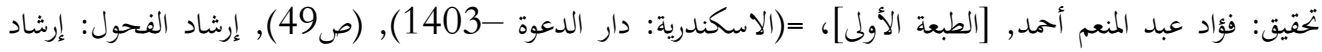

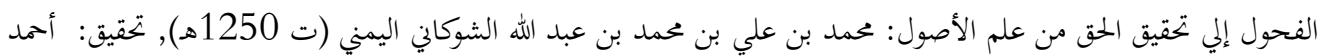

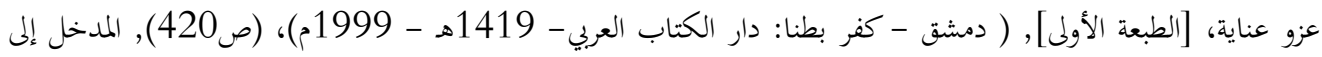

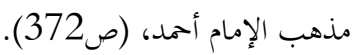

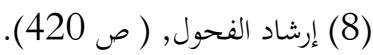

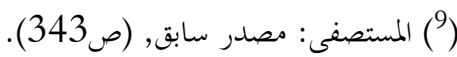
(10) مراتب الإجماع: أبو محمد علي بن أحمد بن سعيد بن حزم الأندلسي القرطبي الظاهري (ت 456هـ), [الطبعة: بدون],

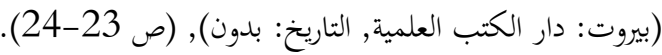

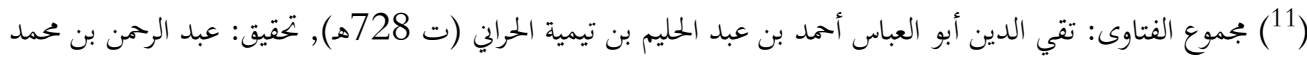

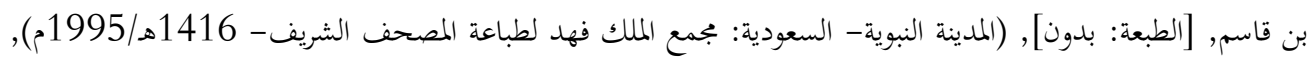

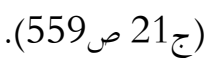

(12) موسوعة الإجماع في الفقه الإسلامي: سعدي أبو حبيب, [الطبعة الخامسة], (بيروت: دار الفكر - 2005)، (ص

$$
\begin{aligned}
& \text { (13) المصدر السابق: (ص20). } \\
& \text { (14) المصدر السابق نفسه. }
\end{aligned}
$$

(15) نقد مراتب الإجماع:ابن تيميه، تحقيق: حسن أحمد إسبر, [الطبعة الأولى], (بيروت: دار ابن حزم - 1419هـ -

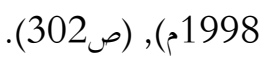

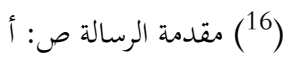

( )

(الاع

(19) الإجماع لابن عبد البر: الشلهوب والشهري, [الطبعة الأولى], (السعودية: دار القاسم- التاريخ: بدون), (ص 6). 